\title{
Predictors of Symptomatic Vasospasm After Subarachnoid Hemorrhage: A Single Center Study of 457 Consecutive Cases
}

\author{
Norbert KOZAK', Dániel BERECZKI², Sándor SZABO³ \\ 'University of Debrecen, Department of Neurology, Debrecen, Hungary \\ ${ }^{2}$ Semmelweis University, Department of Neurology, Budapest, Hungary \\ ${ }^{3}$ University of Debrecen, Deparment of Neurosurgery, Debrecen, Hungary
}

\section{ABSTRACT}

AIM: We set forth to identify predictors of symptomatic vasospasm in patients with subarachnoid hemorrhage (SAH).

MATERIAL and METHODS: We used multivariate logistic regression analysis of the prospective, hospital based, single center register of the Department of Neurosurgery, University of Debrecen, Hungary.

Evaluated patients' characteristics were: sex, age, Hunt-Hess grade on admission, location of aneurysm, thickness of blood clot on initial CT scan (Fisher grade), hypertension.

RESULTS: Between 1987 and 2004, 567 SAH cases were registered, 457 were included in this study. Symptomatic vasospasm developed in $22.5 \%$ of the cases. In univariate analysis, Hunt-Hess grades 2 and 3 and female sex were predictive for symptomatic vasospasm. In multivariate analysis, female sex remained a significant predictor: OR: 1.8 (1.005-3.2).

CONCLUSION: Women are at more danger of developing symptomatic vasospasm after subarachnoid hemorrhage.

KEYWORDS: Subarachnoid hemorrhage, Vasospasm, Fisher grade, Age, Sex

\section{INTRODUCTION}

Subarachnoid hemorrhage (SAH) accounts for a minority of all stroke cases but its impact is severe as it strikes at a fairly young age and it is associated with high case fatality and disease burden. After the hemorrhage itself vasospasm is the leading cause of death and disability in SAH patients (14). Angiographic vasospasm develops in up to $70 \%$ of the patients, whereas symptomatic vasospasm in 20 to $30 \%$ of the cases (7). Several factors were proposed as predictors of vasospasm, such as age, sex, amount of blood on computed tomography (CT) (Fisher grade or other method), admission status etc. Results of these studies are controversial. Furthermore there are significant differences in definitions and methods used in these studies.

The aim of the present study was to identify predictors of symptomatic vasospasm in a prospective database of over
400 consecutive patients with $\mathrm{SAH}$ in a single neurosurgical center in Eastern Hungary.

\section{MATERIAL and METHODS}

\section{Patient Population}

Debrecen is the second largest city in Hungary. It is located in the Eastern part of the country. Data of primary SAH patients admitted or referred to the Department of Neurosurgery at the University of Debrecen between the $1^{\text {st }}$ of January 1987 and the $31^{\text {st }}$ of December 2004 were collected prospectively and entered in an anonymized database. Because University of Debrecen is a referring center of the region, patients are registered not only from Debrecen City, but also from several counties of the region with a catchment area of approximately 700000 inhabitants. SAH was determined by clinical symptoms and neuroimaging findings (CT, angiography). Lumbar 
puncture was performed when CT scan could not confirm $\mathrm{SAH}$ in spite of strong clinical suspicion. Cases resulting from secondary SAH (trauma, coagulation disorder, neoplasm, etc.) were excluded. Evaluated patients' characteristics were: sex, age, presence of aneurysm, Fisher grade (5) on initial CT scan (Table I), hypertension, Hunt-Hess grade (9) on admission (Table II), symptomatic vasospasm, and case fatality. If the patients were not capable of cooperation, relatives were asked for information. We defined symptomatic vasospasm as a clinical entity that includes a new, delayed focal neurological deficit or mental status decline without evidence of any other cause in $\mathrm{SAH}$ patients $(6,19)$.

\section{Statistical Analysis}

Continuous variables were compared by one-way ANOVA, and categorical variables by $x^{2}$ test. Univariate and multivariate logistic regression were applied to test predictive factors for symptomatic vasospasm. The following factors were tested as possible predictors: age (as a continuous variable and also as dichotomized at 50 years of age), sex, hypertension, Hunt-Hess and Fisher grade on admission, site of aneurysm (anterior versus posterior circulation). All of these factors were included in the multivariate logistic regression analysis. Stepwise backward model was applied to find the independent predictors of symptomatic vasospasm. Statistical analyses were performed on Statistical Package of Social Sciences (SPSS) 22 software, SPSS Inc.

\section{RESULTS}

Between 1987 and 2004, 567 SAH cases were registered. In 457 patients we had unequivocal data whether clinical signs of symptomatic vasospasm did or did not appear. These patients were included in the present study. Female patients were significantly older and had hypertension more frequently
(Table III). Case fatality was $32.5 \%$. There was no significant change in case fatality during the observational period. Aneurysms were verified in $94.9 \%$ of the patients.

\section{Vasospasm}

Symptomatic vasospasm developed in $22.5 \%$ of the patients, significantly more frequent in women. Only SAH cases with proved aneurysm were included in the logistic regression models. Applying univariate logistic regression Hunt-Hess grade 2 (OR: 2.9 (1.4-6.2) $\mathrm{p}=0.006$ ) and 3 (OR: 2.4 (1.15.3) $\mathrm{p}=0.037$ ), and female sex (OR: $1.8(1.1-2.8) \mathrm{p}=0.019)$ were predictive for symptomatic vasospasm (Table IV). In multivariate logistic regression (including age, sex, HuntHess and Fisher grades, hypertension, aneurysm site) only female sex (OR: 1.8 (1.005-3.2) $p=0.048$ ) was predictive for symptomatic vasospasm. Age was tested as a continuous variable and also as dichotomized at 50 years of age.

\section{DISCUSSION}

Female preponderance is observed in most SAH study populations (3). Ruptured aneurysms are the cause of SAH in $85 \%$ of the cases (21). In the present study the rate was higher, probably due to referring bias. The case fatality did not change significantly during the observational period.

The rate of symptomatic vasospasm was similar to data in the literature (7).

\section{Amount and Location of Blood}

The predictive validity of the Fisher grade for vasospasm was questioned (19) and a modified Fisher scale was proposed (6). Kramer et al. (12) found that the clinical performance of the modified scale is better. Hijdra et al. (8) developed a more comprehensive grading scale that is superior to the modified

Table I: The Fisher Scale

\begin{tabular}{cl}
\hline Fisher group & Appearance of SAH on CT \\
\hline 1 & No subarachnoid blood visualized \\
\hline 2 & Diffuse thin layer $(<1 \mathrm{~mm})$ \\
\hline 3 & Localized clot and/or thick vertical layer $(>1 \mathrm{~mm})$ \\
\hline 4 & Diffuse or no SAH, but intraventricular or intraparenchymal clot \\
\hline
\end{tabular}

SAH: Subarachnoid hemorrhage.

Table II: The Hunt and Hess Scale

\begin{tabular}{cl}
\hline Hunt and Hess category & Clinical condtition \\
\hline 1 & Asymptomatic, mild headache, slight nuchal rigidity \\
\hline 2 & Moderate to severe headache, nuchal rigidity, no neurologic deficit other than cranial nerve palsy \\
\hline 3 & Drowsiness/confusion, mild focal neurologic deficit \\
\hline 4 & Stupor, moderate-severe hemiparesis \\
\hline 5 & Coma, decerebrate posturing \\
\hline
\end{tabular}


Fisher scale at predicting vasospasm (4), however, the Hijdra scale is cumbersome. The Barrow Neurological Institute Scale was also introduced and found to be more reliable than the Fisher scale (22). It was proposed that not only the amount of blood is important in prediction of vasospasm but the location as well. Abla et al. (1) found greater risk for ruptured pericallosal aneurysms. The distribution of the blood is important even in non-aneurysmal SAH (16). Although due to the earlier time period of the data collection we could not test the newer scales, our results support the necessity of reevaluation of the original Fisher grading scale. In our study the location of the ruptured aneurysm was not predictive.

\section{Sex and Age}

Our results suggest that female gender is predictive for symptomatic vasospasm. There are data that female sex is a risk factor for angiographic vasospasm $(17,18)$, however the majority of the studies have shown no correlation between sex and the risk or incidence of vasospasm (7).

There are controversial reports regarding age $(7,14)$. Several studies suggest that young age is a predictor for symptomatic vasospasm $(2,10,15,20)$, however in our study young age did not predict symptomatic vasospasm. Smith et al. (19) concluded that sex, age, Hunt-Hess and Fisher grades are not predictive. Ryttlefors et al. (18) did not find age to be a significant predictor for either angiographic or symptomatic vasospasm. In Lanzino et al. large study (13) with 906 patients, using 5 age groups, there were more symptomatic vasospasms in the older age groups, but there were no significant difference in angiographic vasospasm among the age groups. Kale et al. (11) found that younger age $(<50)$ predicted for symptomatic

Table III: Patient Characteristics

\begin{tabular}{|c|c|c|c|}
\hline & Total (457) & Men (188) & Women (269) \\
\hline Hypertension & $232 / 456(50.9 \%)$ & $81 / 188$ (43.1\%) & $151 / 268(56.3 \%)^{b}$ \\
\hline Aneurysm & $434 / 457$ (94.9\%) & 176/188 (93.6\%) & $258 / 269$ (95.9\%) \\
\hline ICA & $108(24.9 \%)$ & $34(19.3 \%)$ & $74(28.7 \%)^{c}$ \\
\hline PCA & $1(0.2 \%)$ & $0(0 \%)$ & $1(0.4 \%)$ \\
\hline $\mathrm{ACA}$ & $18(4.1 \%)$ & $7(4 \%)$ & $11(4.2 \%)$ \\
\hline ACom & $151(34.8 \%)$ & $76(43.2 \%)$ & 75 (29.1\%) \\
\hline Basilar & $4(0.9 \%)$ & $2(1.1 \%)$ & $2(0.8 \%)$ \\
\hline Hunt-Hess 1 & $78 / 439$ (17.8\%) & $31 / 179(17.3 \%)$ & $47 / 260(18.1 \%)$ \\
\hline 2 & $193(44 \%)$ & $83(46.4 \%)$ & $110(42.3 \%)$ \\
\hline 3 & $123(28 \%)$ & $48(26.8 \%)$ & $75(28.8 \%)$ \\
\hline 4 & $34(7.7 \%)$ & $14(7.8 \%)$ & $20(7.7 \%)$ \\
\hline 5 & $11(2.5 \%)$ & $3(1.7 \%)$ & $8(3.1 \%)$ \\
\hline Fisher 1 & 13/354 (3.7\%) & $6 / 137(4.4 \%)$ & $7 / 217(3.2 \%)$ \\
\hline 2 & $118(33.3 \%)$ & $42(30.7 \%)$ & $76(35 \%)$ \\
\hline 3 & $111(31.4 \%)$ & $46(33.6 \%)$ & $65(30 \%)$ \\
\hline
\end{tabular}

Denominators show how many patients provided data regarding certain characteristics. ${ }^{a} p=0.007{ }^{b} p=0.005{ }^{c} p=0.058{ }^{d} p=0.012 \quad{ }^{e} p=0.018$ comparing sexes "aneurysmal SAH ACA: Anterior cerebral artery, ACom: Anterior communicating artery, AVM: Arteriovenous malformation, ICA: Internal carotid artery, MCA: Middle cerebral artery, PCA: Posterior cerebral artery, SAH: Subarachnoidal hemorrhage, SD: standard deviation, VA-PICA: Vertebral artery (including posterior inferior cerebellar artery), vsp: Vasospasm. 
Table IV: Predictors of Symptomatic Vasospasm

\begin{tabular}{|c|c|c|c|c|}
\hline & \multicolumn{2}{|c|}{ Univariate analysis } & \multicolumn{2}{|c|}{ Multivariate analysis } \\
\hline Young age $(\leq 50)$ & $1.05(0.7-1.7)$ & 0.843 & $1.2(0.7-2.1)$ & 0.503 \\
\hline Fisher grade 3 & $5.1(0.6-40.6)$ & 0.126 & $4.6(0.6-38.0)$ & 0.153 \\
\hline Fisher grade 4 & $4.4(0.5-35.2)$ & 0.164 & $3.7(0.5-30.8)$ & 0.219 \\
\hline Hunt-Hess 3 & $2.4(1.1-5.3)$ & 0.037 & $1.4(0.5-4.0)$ & 0.528 \\
\hline Sex (female) & $1.8(1.1-2.8)$ & 0.019 & $1.8(1.005-3.2)$ & 0.048 \\
\hline Hypertension & $1.3(0.8-2.0)$ & 0.304 & $0.9(0.5-1.6)$ & 0.695 \\
\hline Aneurysm (anterior) & $2.1(0.5-9.5)$ & 0.327 & $0.8(0.2-4)$ & 0.790 \\
\hline
\end{tabular}

OR: Odds ratio, Cl: Confidence interval, Aneurysm: Anterior vs. posterior circulation.

Table V: Studies Analyzing Multiple Predictors of Symptomatic Vasospasm

\begin{tabular}{|c|c|c|c|c|c|c|}
\hline Study & $\mathbf{N}$ & Young age & Female sex & Fisher grade & $\begin{array}{c}\text { Good } \\
\text { Hunt-Hess* }\end{array}$ & Location \\
\hline Charpentier 1999 & 244 & + & neg & neg & + & neg \\
\hline Smith 2005 & 134 & neg & neg & neg & neg & ND \\
\hline Ryttlefors 2010 & 413 & neg & $+\S$ & ND & ND & ND \\
\hline Current study & 457 & neg & + & neg & neg & neg \\
\hline
\end{tabular}

${ }^{*}$ Hunt-Hess grade 1-2; ${ }^{\mathcal{S}}$ for angiographic vasospasm; ND: no data.

and angiographic vasospasms, whereas sex, Hunt-Hess and Fisher grade on CT were not predictive (Table V).

\section{Others}

In univariate analysis, we found that Hunt-Hess grade 2 and 3 is risk factor for vasospasm. However it is difficult to diagnose symptomatic vasospasm in patients with high Hunt-Hess grade, so we have to be cautious with the interpretation. Even in our study in multivariate analysis Hunt-Hess grade lost its significance.

The study designs, age limits and vasospasm definitions are different in the studies, making it difficult to compare their results and explaining at least partly the observed differences.

The limitation of our study is the long period of data collection. Although the diagnostic procedures did not change during this period, patient characteristics and routine treatment might have changed considerably between 1987 and 2004. However, the outcome of $\mathrm{SAH}$ did not change significantly during the observational period. Furthermore, not being available at the time of data collection, we had to stick to the Fisher grade and could not test the newer CT grading scales in our analysis.

\section{CONCLUSION}

From the analysis of this database, we concluded that the frequency of vasospasm was similar to previously published data. Age and Fisher grade on initial CT scan was not predictive for symptomatic vasospasm. Female sex was predictive.

\section{ACKNOWLEDGEMENTS}

We wish to thank all doctors and hospital staff for their participation in establishing the database. D.B. was partially supported by the grants No KTIA-NAP-13-1-2013-0001 from the Hungarian Brain Research Program, and TAMOP4.2.1.B-09/1/KMR 


\section{REFERENCES}

1. Abla A, Wilson $D$, Williamson $R$, Nakaji $P$, McDougall $C$, Zabramski J, Albuquerque FC, Spetzler RF: The relationship between ruptured aneurysm location, subarachnoid hemorrhage clot thickness, and incidence of radiographic or symptomatic vasospasm in patients enrolled in a prospective randomized controlled trial. J Neurosurg 120:391-397, 2014

2. Charpentier C, Audibert G, Guillemin F, Civit T, Ducrocq X, Bracard S, Hepner H, Picard L, Laxenaire MC: Multivariate analysis of predictors of cerebral vasospasm occurrence after aneurysmal subarachnoid hemorrhage. Stroke 30:1402-1408, 1999

3. de Rooij NK, Linn FH, van der Plas JA, Algra A, Rinkel GJ: Incidence of subarachnoid hemorrhage: A systematic review with emphasis on region, age, gender and time trends. J Neurol Neurosurg Psychiatry 78:1365-1372, 2007

4. Dupont SA, Wijdicks EFM, Manno EM, Lanzino G, Rabinstein AA: Prediction of angiographic vasospasm after aneurysmal subarachnoid hemorrhage: Value of the Hijdra sum scoring system. Neurocrit Care 11:172-176, 2009

5. Fisher CM, Kistler JP, Davis JM: Relation of cerebral vasospasm to subarachnoid hemorrhage visualized by computerized tomographic scanning. Neurosurgery 6:1-9, 1980

6. Frontera JA, Claassen J, Schmidt JM, Wartenberg KE, Temes R, Connolly ES Jr, MacDonald RL, Mayer SA: Prediction of symptomatic vasospasm after subarachnoid hemorrhage: The modified Fisher scale. Neurosurgery 59:21-26, 2006

7. Harrod CG, Bendok BR, Batjer HH: Prediction of cerebral vasospasm in patients presenting with aneurysmal subarachnoid hemorrhage: A review. Neurosurgery 56: 633654, 2005

8. Hijdra A, Brouwers PJ, Vermeulen M, van Gijn J: Grading the amount of blood on computed tomograms after subarachnoid hemorrhage. Stroke 21:1156-1161, 1990

9. Hunt WE, Hess RM: Surgical risk as related to time of intervention in the repair of intracranial aneurysms. J Neurosurg 28:14-20, 1968

10. Jabbarli R, Glasker S, Weber J, Taschner C, Olschewski M, van Velthoven V: Predictors of severity of vasospasm caused by aneurysmal subarachoid hemorrhage. J Stroke Cerebrovasc Dis 22:1332-1339, 2013

11. Kale SP, Edgell RC, Alshekhlee A, Haghighi AB, Sweeny J, Felton J, Kitchener J, Vora N, Bieneman BK, Cruz-Flores S, Abdulrauf S: Age-associated vasospasm in aneurysmal subarachnoid hemorrhage. J Stroke Cerebrovasc Dis 22:2227,2013
12. Kramer AH, Hehir M, Nathan B, Gress D, Dumont AS, Kassel NF, Bleck TP: A comparison of 3 radiographic scales for the prediction of delayed ischemia and prognosis following subarachnoid hemorrhage. J Neurosurg 109:199-207, 2008

13. Lanzino G, Kassel N, Germanson T, Kongable GL, Truskowski LL, Torner JC, Jane JA: Age and outcome after aneurysmal subarachnoid hemorrhage: Why do older patients fare worse? J Neurosurg 85:410-418, 1996

14. Lee Y, Zuckerman SL, Mocco J: Current controversies in the prediction, diagnosis, and management of cerebral vasospasm: Where do we stand? Neurol Res Int 2013:373458, 2013

15. Magge SN, Chen HI, Ramakrishna R, Cen L, Chen Z, Elliott JP, Winn HR, Le Roux PD: Association of a younger age with an increased risk of angiographic and symptomatic vasospasm following subarachnoid hemorrhage. J Neurosurg 112:12081215,2010

16. Raya A, Zipfel G, Diringer M, Dacey R, Derdeyn C, Rich K, Chicoine MR, Dhar R: Pattern not volume of bleeding predicts angiographic vasospasm in nonaneurysmal subarachnoid hemorrhage. Stroke 45:265-267, 2014

17. Rosenorn J, Eskesen V, Schmidt K: Clinical features and outcome in females and males with ruptured intracranial saccular aneurysms. Br J Neurosurg 7:287-290, 1993

18. Ryttlefors M, Enblad P, Ronne-Engström E, Persson L, llodigwe D, Macdonald RL: Patient age and vasospasm after subarachnoid hemorrhage. Neurosurgery 67:911-917, 2010

19. Smith ML, Abrahams JM, Chandela S, Smith, MJ, Hurst RW, Le Roux, PD: Subarachnoid hemorrhage on computed tomography scanning and the development of cerebral vasospasm: The Fisher grade revisited. Surg Neurol 63:229 235, 2005

20. Torbey MT, Hauser TK, Bhardwaj A, Williams MA, Ulatowski JA, Mirski MA, Razumovsky AZ: Effect of age on cerebral blood flow velocity and incidence of vasospasm after aneurysmal subarachnoid hemorrhage. Stroke 32:2005-2011, 2001

21. van Gijn J, Kerr RS, Rinkel GJE: Subarachnoid hemorrhage. Lancet 369:306-318, 2007

22. Wilson DA, Nakaji $P$, Abla AA, Uschold TD, Fusco DJ, Oppenlander ME, Albuquerque FC, McDougall CG, Zabramski JM, Spetzler RF: A simple and quantitative method to predict symptomatic vasospasm after subarachnoid hemorrhage based on computed tomography: Beyond the Fisher scale. Neurosurgery 71:869-875, 2012 